\title{
Meta-analysis to Assess the Impact of Centre's Heart Transplant Status and Volume on in-hospital Outcomes Following Extracorporeal Membrane Oxygenation for Refractory Post-cardiotomy Cardiogenic Shock
}

Mariusz Kowalewski ( $\sim$ kowalewskimariusz@gazeta.pl)

Centralny Szpital Kliniczny MSW w Warszawie https://orcid.org/0000-0002-5478-3245

\section{Giuseppe Raffa}

Istituto Mediterraneo per i Trapianti e Terapie ad Alta Specializzazione

Kamil Zielinski

Warszawski Uniwersytet Medyczny

Musab Alanazi

Maastricht Universitair Medisch Centrum+

Martijn Gilbers

Maastricht Universitair Medisch Centrum+

Sam Heuts

Maastricht Universitair Medisch Centrum+

Ehsan Natour

Maastricht Universitair Medisch Centrum+

Elham Bidar

Maastricht Universitair Medisch Centrum+

Rick Schreurs

Maastricht Universitair Medisch Centrum+ Oncologiecentrum

Thijs Delnoij

Maastricht Universitair Medisch Centrum+

\section{Rob Driessen}

Maastricht Universitair Medisch Centrum+

Jan Willem Sels

Maastricht Universitair Medisch Centrum+ Oncologiecentrum

Marcel van de Poll

Maastricht Universitair Medisch Centrum+ Oncologiecentrum

\section{Paul Roekaerts}

Maastricht Universitair Medisch Centrum+ Oncologiecentrum 


\section{Paolo Meani}

Maastricht Universitair Medisch Centrum+ Oncologiecentrum

Jos Maessen

Maastricht Universitair Medisch Centrum+ Oncologiecentrum

\section{Piotr Suwalski}

Centralny Szpital Kliniczny MSW w Warszawie

\section{Roberto Lorusso}

Maastricht Universitair Medisch Centrum+ Oncologiecentrum

\section{Research article}

Keywords: Extracorporeal Membrane Oxygenation; Extracorporeal Life Support; Cardiogenic Shock; MetaAnalysis

Posted Date: August 8th, 2019

DOl: https://doi.org/10.21203/rs.2.12508/v1

License: (c) (1) This work is licensed under a Creative Commons Attribution 4.0 International License. Read Full License

Version of Record: A version of this preprint was published at BMC Cardiovascular Disorders on January 9th, 2020. See the published version at https://doi.org/10.1186/s12872-019-01317-y. 


\section{Abstract}

Background: Postcardiotomy cardiogenic shock (PCS) that is refractory to inotropic support remains a major concern in cardiac surgery and is almost universally fatal unless treated with mechanical support. While reported mortality rates on ECMO vary from center to center, aim of the current report is assess if the outcomes differ between centres according to volume and heart transplantation status. Methods: A systematic search was performed according to PRISMA statement using PubMed/Medline databases between 2010 and 2018. Relevant articles were scrutinized and included in the meta-analysis only if reporting in-hospital/30-day mortality and heart transplantation status of the centre. Differences were assessed by means of subgroup meta-analysis and meta-regression. Results: Fifty-four studies enrolling $\mathrm{N}=4,421 \mathrm{ECMO}$ patients were included. Of those, 6 series were performed in non-HTx centres (204 pts;4.6\%). Overall 30-day survival (95\% Confidence Intervals) was 35.3\% (32.5-38.2\%) and did not statistically differ between non-HTx: 33.3\% (26.8-40.4\%) and HTx centres: 35.7\% (32.7-38.8\%); Pinteraction $=0.531$. There was no impact of centre volume on survival as well: $ß$ coef $=0.0006 ; P=0.833$. No statistical differences were seen between HTx and non-HTx with respect to ECMO duration, limb complications, reoperations for bleeding, kidney injury and sepsis. There were however significantly less neurological complications in the HTx as compared to non-HTx centres: $11.9 \%$ vs $19.5 \%$ respectively; $\mathrm{P}=0.009$; an inverse relationship was seen for neurologic complications in centres performing more ECMOs annually $ß$ coef $=-0.0066 ; P=0.031$. Weaning rates and bridging to $H T x$ and/or VADs were higher in HTx facilities. Conclusions: There was no apparent difference in survival after ECMO implantation for refractory PCS according to centre's ECMO volume and transplantation status. Potentially different risk profiles of patients in these centres must be taken account for before definite conclusions are drawn.

\section{Background}

Extracorporeal Membrane Oxygenation (ECMO) use is increasing; yet, it still does represent a resourceconsuming modality of treatment and, in majority of cases, is seen as a last resort for patients who, otherwise, would inevitably die [1-5]. Postcardiotomy- and ST-elevation myocardial infarction (MI) complicating- cardiogenic shock (CS) were two most frequent indications for VA-ECMO implantation in the United States until 2011 [3-5]. Despite growing worldwide utilization and experience in mechanical circulatory support (MCS), in particular, in-hospital outcomes while on ECMO have not shown substantial progress [6]; little is still known of who benefits most from ECMO not to mention cost effectiveness of such long and advanced therapy [7]. European Society of Cardiology guidelines therefore cautiously assigned ECMO class of recommendation Ilb, level of evidence $\mathrm{C}$ for the management of cardiogenic shock in STEMI [8].

Unlike STEMIs, cardiac surgical patients are usually characterized by substantial pre-ECMO comorbidities and more advanced age [9]. All these factors, individually or in association, may inhibit the potential of myocardium to recover after the surgery and/or hamper favorable body response to prolonged MCS. Indeed, in some patients, prolonged MCS does not lead to improved cardiac function or organ integrity; clinicians are therefore forced to bridge the patient; since bridge to recovery is no longer an option, more 
advanced treatments, such as heart transplantation $(\mathrm{HTx})$ or long-lasting ventricular assist devices (VADs) remain. Not all heart surgery centres perform HTx, and not all of them perform VADs.

We therefore, undertook current systematic review and meta-analysis to assess to which extent do the inhospital outcomes differ across PCS-ECMO recipients in heart transplantation- as compared to nontransplant units to account for readability of ECMO teams and potentially shorter bridging times in these facilities. Additionally, we investigated on how are the in-hospital outcomes affected by centre's volume and annual ECMO institution rates to account for differences in between centres experience.

\section{Material And Methods}

\section{Data sources and search strategy}

This systematic review and meta-analysis was performed in accordance with the Preferred Reporting Items for Systematic Reviews and meta-analyses (PRISMA) statement [10]. The PRISMA checklist is available as Appendix Table 1. To best reflect current clinical practice, relevant studies to be included were searched for between year 2000 until March $31^{\text {st }}$ 2018, through PubMed, EMBASE, CINAHL, the Web of Science, the Cochrane Register of Controlled Clinical Trials (CENTRAL) and Google Scholar. Abstracts were eligible for detailed assessment if available online and reporting outcomes of interest. The search term was: "extracorporeal membrane oxygenation" and "extracorporeal life support". No language restrictions were imposed. References of original articles were reviewed manually and cross-checked for other relevant reports.

\section{Selection criteria and quality assessment}

Studies were included if they met all of the following criteria: 1) human study; 2) studies assessing survival after ECMO instituted for postcardiotomy refractory cardiogenic shock; 3) study reporting institutional outcomes that for ECMO indication combined postcardiotomy and non-postcardiotomy cardiogenic shock, but postcardiotomy comprised majority of cases; 4) studies combining nonpostcardiotomy and postcardiotomy cardiogenic shock patients but reporting outcomes of interest separately for the latter. Studies were only excluded if: 1) paediatric and congenital heart surgery-related studies; 2) animal studies; 3 ) conducted in the setting of veno-venous ECMO for respiratory distress following heart surgery; and 4) studies not reporting survival/mortality rates. Studies were only eligible if reporting the transplant status of the centre; whenever this was not retrievable from the individual study, institutional website was searched for information regarding range of procedures performed. Lack of clear indication whether the centre performs heart transplantation led to exclusion of the study. Similarly, registries incorporating multiple centres but not reporting the status for single facilities were not considered. Reviews and case reports were not considered as well. 
Two independent reviewers (P.M. and K. Z.) selected the studies for inclusion, extracted studies, as well as patient characteristics of interest and relevant outcomes. Two authors (P.M. and K. Z.) independently assessed the trials' eligibility and risk of bias. Risk of bias at the individual study level was assessed using the ROBINS-I tool (Risk of Bias in Not-randomized Studies-of Interventions) [11]. Any divergences were resolved by a third reviewer (R. L.) and quantified using the approach of Cohen's kappa [12].

\section{Endpoint selection}

The primary endpoint was in-hospital survival. Secondary endpoints were in-hospital cerebrovascular events (CVE), limb complications, bleeding or reoperation for bleeding, sepsis and acute kidney failure w/wo continuous veno-venous hemofiltration (CVVH). Bridging to VAD and/or HTx was analysed as well. Outcome definitions were the ones adopted by the investigators of the included studies.

\section{Statistical analysis}

Statistical analyses were performed in Comprehensive Meta-Analysis, v. 2 (Biostat, Englewood, NJ). The results are expressed as pooled untransformed proportions (eg. event rates (\%) and means with their $95 \%$ confidence intervals $(\mathrm{Cl})$. Heterogeneity across studies was evaluated using the $P$ test. Where available, we digitised Kaplan-Meier curves using Engauge Digitizer 9.5 (Mark Mitchell, Torrance, CA) and reconstructed time-to-event data using the algorithm specified by Guyot et al. [13]. To control for the anticipated heterogeneity among observational studies, absolute values and means were pooled using random effects models. Studies were stratified a priori based on the centre status (HTx vs non-HTx performing centre); the interaction coefficient (Q-value) is provided for the comparison HTx vs non-HTx along with respective $\mathrm{P}_{\text {interaction. }}$. Additionally, we investigated if $\mathrm{HTx}$ and non-HTx status had influence on ECMO duration, weaning rates, bridging to HTX/VAD rates; and further if ECMO duration and weaning rates in these centres correlated with bridging to HTx/VAD by means of meta-regression analyses [14]. Similarly meta-regression approach was used to determine whether annual ECMO institution rate for centre reporting such, affects the survival and remaining in-hospital outcomes. Annual ECMO institution rate was calculated by dividing $\mathrm{n}$. of study subjects by study duration period. Sensitivity analyses were performed by excluding from analyses single studies, one at a time, and repeating the calculations. Subgroup analyses were performed for survival endpoint by dividing the studies into distinctive strata (by mean and median annual ECMO institution rate as well as in tertiles and quartiles) and reporting

respective $P_{\text {interaction }}$ for between subgroup comparison. Publication bias was assessed 1 ) by visual approach plotting log event rate against standard error in the funnel plot; and 2) by linear regression approach [15].

\section{Results}


Initial search process yielded 22,609 records; of these, 183 abstracts were retrieved for scrutiny based on the item's title. Registries were excluded since they incorporated both HTx and non-HTx centres [16-18]. Following detailed assessment, 54 studies ( $N=4,421$ patients) [list of references to included studies] met inclusion criteria and entered quantitative analyses. PRISMA flow chart is available as Figure 1. Included studies were divided into HTx vs non-HTx centres subgroups: 48 studies including 4,217 (95.4\%) patients were conducted in HTx- whereas 6 studies $(\mathrm{N}=204)$ in non-HTx centres. Prevalence of ECMO ranged from $0.26 \%$ [70] to $3.35 \%$ [28]. Patients receiving ECMO at HTx centres were significantly younger than their non-HTx counterparts $57.2 \pm 1.6$ vs $64.2 \pm 1.6 \mathrm{P}<0.001$. CABG was most frequent procedure in both HTx and non-HTx centres $33.7 \%$ and $30.9 \%$ followed by valvular (25.1\% and $21.1 \%$ ) and combined surgeries (16.5\% and $26.5 \%)$. Detailed characteristics of included studies as well as patients' baseline and surgical data are available in Table 1. Publication bias analysis along with reasons for bias risk increase is available as Appendix Table 2; studies were judged to me moderate to severe risk of bias as none previously compared directly HTx vs non-HTx centre performance; no signs of asymmetry were seen on visual inspection of funnel plot for primary endpoint (Appendix Figure 1).

\section{ECMO strategy}

In the studies that reported procedural details, ECMO was established during the initial cardiac surgery in $42.7 \%$ of cases because of circulatory instability during or immediately after weaning from cardiopulmonary bypass. ECMO was initiated in the OR in $56.5 \%$ of patients $(50.1-62.7 \%)$, followed by ICU, cardiac catheterization laboratory, telemetry floor and emergency department. A statistical trend was observed for more common placement of ECMO in the OR than other locations in non-HTx - as compared to HTx centres: $64.5 \%$ (52.9-74.6\%) vs 53.2\% (45.6-60.7\%); $P=0.108$. Peripheral cannulation was preferred approach (69.0\%) for ECMO institution. Median ECMO duration in the entire series was 5 (IQR: 3.3-6.0 days); without apparent differences between HTx (mean weighted average $=4.92$ days) vs nonHTx- (5.04 days) centres. The details of procedural characteristics are available as Appendix Table 3. Successful weaning from ECMO was most often defined as decannulation after $>48$ hours. Overall, estimated $55.3 \%$ patients were weaned from ECMO with the weaning rates ranging from $31.4-100 \%$ in the entire series. There was a signal for higher weaning rates across $\mathrm{HTx}$ vs non-HTx centres $(56.6 \%$ vs $50.4 \% ; P=0.118)$.

\section{Survival and complications while on ECMO}

Reported causes of death were divided into "while on-ECMO" and "after weaning" and are available in Appendix Table 3. Fifty-three studies (4,367 patients) contributed to the analysis of survival: Overall, 1,527 patients survived to hospital discharge which translated to estimated overall survival of $35.3 \%$ (32.5-38.2\%). There was no difference between HTx - (35.7\% [32.7-38.8\%]) and non-HTx centres (33.3\% [26.8-40.4\%]) $p=0.531$ in random effects model. Figure 2A. In meta-regression, there was no impact of centre volume on survival as well: $\beta_{\text {coef }}=0.0006 ; P=0.833$ (Figure $2 B$ ). 
Limb complications incidence was reported in 30 studies (2,766 pts). Overall, 424 patients $(13.0 \%$ [10.5$16.0 \%]$ ) had limb complications; Figure 3A; in the analysis stratified by centre status there was no difference between HTx - (13.0\% [10.4-16.1\%] and non-HTx centres (13.35 [6.4-26.1\%] P = 0.919). In meta-regression, there was no impact of centre volume on incidence of limb complications: $\beta_{\text {coef }}=$ $0.0043 ; P=0.342$ (Figure 3B).

There were significantly less neurological complications in the HTx as compared to non-HTx centres: overall 385 patients (33 studies) experienced neurological complications (14.1\% [11.8-16.8\%]) Figure 4A; among those 88 brain deaths (7.9\% [5.6-11.0\%] occurred. Appendix Figure 2. Neurologic complications in non-HTx centres followed in $19.5 \%(14.5-25.8 \%)$ as compared to $11.9 \%(9.5-14.8 \%)$ in HTx centres; $\mathrm{P}$ $=0.009$. In meta-regression, less neurologic complications and brain deaths were seen in centres with higher annual ECMO institution rate: $\beta_{\text {coef }}=-0.0066 ; P=0.031$ (Figure 4B) and $B_{\text {coef }}=-0.0515 ; P=$ 0.071 (Appendix Figure 3) respectively.

Thirty-three studies enrolling 2,832 patients reported reoperations for bleeding; these were necessary in 1,232 cases $(41.2 \%$ [35.6-47.1\%]) in the entire series without statistical differences between HTx: $39.5 \%$ (33.6-45.8\%); and non-HTx centres: 52.6\% (36.6-68.0\%); $\mathrm{P}=0.139$. Figure 5. In meta-regression, there was no impact of centre volume on incidence of reoperation for bleeding: $\beta_{\text {coef }}=-0.0012 ; P=0.489$ (Appendix Figure 4). Sepsis has complicated 385 ECMO cases $20.7 \%$ (17.0-24.9\%) but there were again no differences between HTx - (19.5\% [15.5-24.1\%]) and non-HTx centres (25.2\% [16.9-36.0\%]); P = 0.259 in the meta-analysis (Figure 6) nor in meta-regression of centre's volume impact (Appendix Figure 5) $\left(B_{\text {coef }}=-0.0040 ; P=0.692\right.$ ). In the analysis of AKI with or without CVVH (Appendix Table 4 lists AKI definitions across included studies) less AKIs in non-HTx centres were seen but the difference was not significant $(p=0.220)$ Figure 7: Total incidence of AKI was 47.3\% (41.5-53.1\%)-1,513 reported cases; in non-HTx centres AKI estimated rate was $38.7 \%(25.5-53.7 \%)$ as compared to $48.8 \%(42.5-55.1 \%)$ as observed in HTx centres; no effect of centre's annual ECMO institution rate on AKI incidence was demonstrated in meta-regression $\left(B_{\text {coef }}=-0.0012 ; P=0.488\right)$ Appendix Figure 6.

\section{ECMO as bridging therapy}

Eighty-six (estimated rate 3.5\% [1.8-6.6\%]) patients were bridged to heart transplantation. Of those, all were bridged to HTx in HTx centres. Off note, one reported patient died on ECMO after transfer from nonHtx centre to the referral hub centre while waiting for heart transplantation [70]. ECMO bridging to shortor long-term VAD ensued in 99 patients (4.3\% [2.8-6.5\%]); there were again no instance of reported bridging to VADs in non-HTx centres.

\section{Additional analyses:}


In several conducted meta-regressions, no impact of centre status on survival $\left(B_{\text {coef }}=0.1418 ; P_{\text {slope }}=\right.$ 0.555 ) or ECMO duration ( $B_{\text {coef }}=0.0052$; $P_{\text {slope }}=0.833$ ) could be demonstrated. Centre status positively, yet non-significantly, correlated with higher weaning rates $\left(B_{\text {coef }}=0.2651 ; P_{\text {slope }}=0.601\right)$. Appendix Figure 7 and 8 summarize subgroup analyses performed for survival rates as divided by annual number of ECMOs performed. In sensitivity analysis for survival performed deleting single studies, one at a time, and repeating the calculations, no single study effect was seen changing neither direction nor the magnitude of the estimates.

\section{Discussion}

To the best of our knowledge, the current meta-analysis represents the first attempt to address the differences in in-hospital outcomes of patients supported with VA-ECMO for refractory PCS between HTX and non-HTx centres. This research was aimed to investigate further factors other than the well known patients' clinical status and procedure type that may affect the final outcome in PCS-ECMO patient. The care center with experience in dealing with acute and chronic end stage heart failure with expertise and prompt resources availability (medium and long term mechanical circulatory support and heart transplantation) as factor potentially affecting this outcome was the primary hypothesis of our study.

VA-ECMO is increasingly used for cardiorespiratory support in patients affected by refractory cardiogenic shock or cardiac arrest after cardiac surgery. [2] Despite that growing worldwide utilization and experience, ECMO in-hospital outcomes have not shown substantial progress. Conversely, a trend towards worse survival rates, reaching a disappointing $15 \%$ has been recently reported in another analysis of the Extracorporeal Life Support Organization registry [2]. Patients undergoing heart surgery usually present with substantial pre-ECMO comorbidities, more advanced age and above all different stages of developed heart failure. All these factors, individually or in association influence the capability of the myocardium to recover after the surgery and thus preclude favorable body response to prolonged MCS. Unfortunately, in a considerable proportion of patients, the MCS regardless of its duration, does not prompt to improved cardiac function or organ integrity; in turn, clinicians are forced to bridging the patient to more advanced treatments, such as HTx or VADs. The insights from important recently available study by Distelmeier [20] are that prolonging of VA-ECMO duration is associated with a disproportionate mortality at early and later stages. In fact, lack of cardiac function improvement within 7 days post-op. was indicative of futile support in the analysis. Consequently, this leads to conclusion that perhaps HTx or VADs in such ECMO-supported patients should be used much sooner, just in time to prevent lifethreatening complications

Such hypothesis led to conception of the current study which is the first to compare, although in indirect fashion, the outcomes between $\mathrm{HTx}$ and non-HTx performing centres in patients undergoing ECMO treatment for refractory PCS. The first consideration come from the study population of this metaanalysis: the majority of the patients $(4,217$ over 4,421$)$ and number of reports (48 over 54 ) come from HTx centers suggesting that 1 ) cardiac surgery population may show similar or higher risk profiles in HTx centres thus, an increased baseline risk for developing PCS and 2) ECMO represents a tool routinely used 
for the treatment of refractory PCS in the HTx units; 3 ) there exists an unexplained underreporting from non-HTx centres with regard to the perioperative outcomes and in particular of patients undergoing ECMO treatment. Regardless, our main findings were that among patients with PCS no differences in 30 day/inhospital mortality were observed between heart transplantation centres as compared to non-transplant units. This was also confirmed in a subgroup analysis. While neutral, this finding implies similar mortality rates among patients operated on in HTx and long-term assistance facilities as compared to lower risk cardiac surgery patients operated in non-transplant units, given their respective potentially higher and lower baseline risk.

Second, there was no difference between the centers type with respect to limb complications, reoperation for bleeding, sepsis and acute renal injury with or without dialysis, yet neurological complications occurred less frequently in HTx centres. Neurologic complications are presumably a multifactorial entity with pre-ECMO illness severity and treatments, ECMO management, and post-ECMO events all contributing to CNS injury rates in these patients. Loss of cerebral autoregulation during severe arterial hypertension or hypotension, thromboembolic events, haemorrhage related to anticoagulation use, cerebral vasospasm, and secondary brain injury from reactive tissue oedema around an area of focal CNS injury have all been implicated in the genesis of brain injury in VA-ECMO patients. Although neurologic injury during VA-ECMO remains poorly defined in adult cohorts [16,21-23], prior investigations comprehensively report neurologic complications occurrence in $6-17 \%$ in adults supported with VAECMO for postcardiotomy cardiorespiratory failure [21,24,25]. What seems even more illustrative, postmortem examination in adults supported with VA-ECMO has shown that neurologic injury may be clinically undetected in $23-50 \%$ of cases $[26,27]$. In the current analysis, we saw neurologic complications more frequent in non-HTx centres. While this could not be accounted for in that type of analyses, the "over-delay" to ECMO commencement in the institutions with lower experience with circulatory support systems (be that ECMO or VADs) may have played a role in the excess of strokes in this population.

Finally, patients on ECMO bridged to HTx or mechanical circulatory support are reported only in the HTx units. Single patients in non-HTx institutions died while waiting for referral to HTx hub after the decision to transplant was met. From the technical standpoint, is noteworthy to underline that the were no differences in the ECMO duration between the two centers, yet notice must me made of statistical trend for the different ECMO location placement and weaning rate; that is, ECMO was instituted in the OR more frequently in non-HTx centres but again since delay to ECMO was seldom reported, we cannot address the issue whether this might had affected patient outcome. On the other hand, this may further suggest an easier applicability of ECMO in locations other than OR in HTx-centres with possibly prompt ECMO team availability as compared to the non-HTx units.

Conclusions: There was no apparent difference in survival after ECMO implantation for refractory PCS between centres which perform heart transplantations and those which do not. Potentially different risk profiles of patients in these centres must be taken account for before definite conclusions are drawn. 


\section{Abbreviations}

PCS-postcardiotomy cardiogenic shock

ECMO-extracorporeal membrane oxygenation

MCS-mechanical circulatory support

PRISMA-preferred item reporting for systematic reviews and meta-analyses

HTx-heart transplantation

VAD-ventricle assist device

STEMI-ST segment elevation myocardial infarction

VA-ECMO-veno-arterial extracorporeal membrane oxygenation

ROBINS-I-Risk of Bias in Not-randomized Studies-of Interventions

CVE-cerebrovascular event

CVVH-continuous veno-venous hemofiltration

OR-odds ratio

95\% Cls-95\% Confidence Intervals

AKI-acute kidney injury

ELSO-Extracorporeal Life Support Organization

CNS-central nervous system

\section{Declarations}

\section{Ethics approval and consent to participate:}

NA

\section{Consent for publication:}

NA 


\section{Availability of data and material:}

All data are available

\section{Competing interests:}

The authors declare that they have no competing interests

\section{Funding:}

None

\section{Authors' contributions:}

Conception and design: MK, GR, JM, PS, RL

Data acquisition: $M K, K Z, M A, M G, E N, E B, P M$

Data analysis: MK, GR, MA, SH, RS, TD, RD, MvdP, JWS,

Data interpretation: $\mathrm{MK}, \mathrm{SH}, \mathrm{RS}, \mathrm{TD}, \mathrm{JWS}, \mathrm{PR}, \mathrm{JM}, \mathrm{RL}$

Drafting of the MS: MK, KZ, GR, RL

Critical revision: MA, MG, EN, EB, RS, TD, RD, JWS, MvdP, PR, PM, JM, PS

All authors read and approved the final manuscript

\section{Acknowledgements:}

None

\section{References}

1. Lawler PR, Silver DA, Scirica BM, Couper GS, Weinhouse GL, Camp PC, Jr. Extracorporeal membrane oxygenation in adults with cardiogenic shock. Circulation 2015;131:676-680.

2. Whitman GJ. Extracorporeal membrane oxygenation for the treatment of postcardiotomy shock. $J$ Thorac Cardiovasc Surg. 2017;153:95-101

3. Stretch R, Sauer CM, Yuh DD, Bonde P. National trends in the utilization of short-term mechanical circulatory support: Incidence, outcomes, and cost analysis. J Am Coll Cardiol 2014;64:1407-1415 
4. McCarthy FH, McDermott KM, Kini V, Gutsche JT, Wald JW, Xie D et al. Trends in U.S. Extracorporeal membrane oxygenation use and outcomes: 2002-2012. Semin Thorac Cardiovasc Surg. 2015;27:81-88

5. Karagiannidis C, Brodie D, Strassmann S, Stoelben E, Philipp A, Bein T et al. Extracorporeal membrane oxygenation: Evolving epidemiology and mortality. Intensive Care Med. 2016;42:889-896

6. Maxwell BG, Powers AJ, Sheikh AY, Lee PH, Lobato RL, Wong JK. Resource use trends in extracorporeal membrane oxygenation in adults: An analysis of the nationwide inpatient sample 1998-2009. J Thorac Cardiovasc Surg 2014;148:416-421.

7. Monaco F, Belletti A, Bove T, Landoni G, Zangrillo A. Extracorporeal membrane oxygenation: Beyond cardiac surgery and intensive care unit: Unconventional uses and future perspectives. J Cardiothorac Vasc Anesth. 2018;32:1955-1970

8. Ibanez B, James S, Agewall S, Antunes MJ, Bucciarelli-Ducci C, Bueno H et al. 2017 ESC guidelines for the management of acute myocardial infarction in patients presenting with st-segment elevation: The task force for the management of acute myocardial infarction in patients presenting with stsegment elevation of the european society of cardiology (esc). Eur Heart J. 2018;39:119-177

9. Saxena P, Neal J, Joyce LD, Greason KL, Schaff HV, Guru P et al. Extracorporeal membrane oxygenation support in postcardiotomy elderly patients: The mayo clinic experience. Ann Thorac Surg. 2015;99:2053-2060

10. Liberati A, Altman DG, Tetzlaff J, Mulrow C, Gotzsche PC, loannidis JP et al. The PRISMA statement for reporting systematic reviews and meta-analyses of studies that evaluate healthcare interventions: Explanation and elaboration. BMJ. 2009;339:b2700

11. Sterne JA, Hernan MA, Reeves BC, Savovic J, Berkman ND, Viswanathan M et al. Robins-I: A tool for assessing risk of bias in non-randomised studies of interventions. BMJ. 2016;355:i4919

12. Blackman NJ, Koval JJ. Interval estimation for Cohen's kappa as a measure of agreement. Stat Med. 2000;19:723-41.

13. Guyot $P$, Ades AE, Ouwens MJ, Welton NJ. Enhanced secondary analysis of survival data: Reconstructing the data from published kaplan-meier survival curves. BMC Med Res Methodol. 2012;12:9

14. Stijnen T, Hamza TH, Ozdemir P. Random effects meta-analysis of event outcome in the framework of the generalized linear mixed model with applications in sparse data. Stat Med. 2010;29:3046-67.

15. Sterne JA, Sutton AJ, loannidis JP, Terrin N, Jones DR, Lau J, et al. Recommendations for examining and interpreting funnel plot asymmetry in meta-analyses of randomised controlled trials. BMJ. 2011;343:d4002.

16. Chen SW, Tsai FC, Lin YS, Chang CH, Chen DY, Chou AH et al. Long-term outcomes of extracorporeal membrane oxygenation support for postcardiotomy shock. J Thorac Cardiovasc Surg. 2017;154:469-477 e462

17. Santarpino G, Ruggieri VG, Mariscalco G, Bounader K, Beghi C, Fischlein T et al. Outcome in patients having salvage coronary artery bypass grafting. Am J Cardiol. 2015;116:1193-1198 
18. Lorusso R, Gelsomino S, Parise O, Mendiratta P, Prodhan P, Rycus P et al. Venoarterial extracorporeal membrane oxygenation for refractory cardiogenic shock in elderly patients: Trends in application and outcome from the extracorporeal life support organization (ELSO) registry. Ann Thorac Surg. 2017;104:62-69

19. Di Mauro M, Lorusso R. Time is your best friend, but it soon becomes your worst enemy: The conflict of venoarterial extracorporeal membrane oxygenation in cardiac surgery. J Thorac Cardiovasc Surg. 2018;155:2477-2478

20. Distelmaier K, Wiedemann D, Binder C, Haberl T, Zimpfer D, Heinz G, Koinig H, Felli A, Steinlechner B, Niessner A, Laufer G, Lang IM, Goliasch G. Duration of extracorporeal membrane oxygenation support and survival in cardiovascular surgery patients. J Thorac Cardiovasc Surg. 2018;155:24712476

21. Wu MY, Lin PJ, Lee MY, Tsai FC, Chu JJ, Chang YS et al. Using extracorporeal life support to resuscitate adult postcardiotomy cardiogenic shock: Treatment strategies and predictors of shortterm and midterm survival. Resuscitation. 2010;81:1111-1116

22. Zangrillo A, Landoni G, Biondi-Zoccai G, Greco M, Greco T, Frati G et al. A meta-analysis of complications and mortality of extracorporeal membrane oxygenation. Crit Care Resusc. 2013;15:172-178

23. Hei F, Lou S, Li J, Yu K, Liu J, Feng Z et al. Five-year results of 121 consecutive patients treated with extracorporeal membrane oxygenation at fu wai hospital. Artif Organs. 2011;35:572-578

24. Rastan AJ, Dege A, Mohr M, Doll N, Falk V, Walther T et al. Early and late outcomes of 517 consecutive adult patients treated with extracorporeal membrane oxygenation for refractory postcardiotomy cardiogenic shock. J Thorac Cardiovasc Surg. 2010;139:302-311, 311 e301

25. Ko WJ, Lin CY, Chen RJ, Wang SS, Lin FY, Chen YS. Extracorporeal membrane oxygenation support for adult postcardiotomy cardiogenic shock. Ann Thorac Surg. 2002;73:538-545

26. Rastan AJ, Lachmann N, Walther T, Doll N, Gradistanac T, Gommert JF et al. Autopsy findings in patients on postcardiotomy extracorporeal membrane oxygenation (ecmo). Int J Artif Organs. 2006;29:1121-1131

27. Mehta A, Ibsen LM. Neurologic complications and neurodevelopmental outcome with extracorporeal life support. World J Crit Care Med. 2013;2:40-47

\section{References to included studies:}

1. Acheampong B, Johnson JN, Stulak JM, Dearani JA, Kushwaha SS, Daly RC, Haile DT, Schears GJ. Postcardiotomy ecmo support after high-risk operations in adult congenital heart disease. Congenit Heart Dis. 2016;11:751-755 1.

2. Bakhtiary F, Keller H, Dogan S, Dzemali O, Oezaslan F, Meininger D, Ackermann H, Zwissler B, Kleine P, Moritz A. Venoarterial extracorporeal membrane oxygenation for treatment of 
cardiogenic shock: Clinical experiences in 45 adult patients. J Thorac Cardiovasc Surg. 2008;135:382-388

3. Beckmann E, Ismail I, Cebotari S, Busse A, Martens A, Shrestha M, Kuhn C, Haverich A, Fegbeutel C. Right-sided heart failure and extracorporeal life support in patients undergoing pericardiectomy for constrictive pericarditis: A risk factor analysis for adverse outcome. Thorac Cardiovasc Surg. 2017;65:662-670

4. Beiras-Fernandez A, Deutsch MA, Kainzinger S, Kaczmarek I, Sodian R, Ueberfuhr P, Meiser B, Schmoeckel M, Reichart B, Brenner P. Extracorporeal membrane oxygenation in 108 patients with low cardiac output - a single-center experience. Int J Artif Organs. 2011;34:365-373

5. Biancari F, Dalen M, Perrotti A, Fiore A, Reichart D, Khodabandeh S, Gulbins H, Zipfel S, Al Shakaki M, Welp H, Vezzani A, Gherli T, Lommi J, Juvonen T, Svenarud P, Chocron S, Verhoye JP, Bounader K, Gatti G, Gabrielli M, Saccocci M, Kinnunen EM, Onorati F, Santarpino G, Alkhamees K, Ruggieri VG, Dell'Aquila AM. Venoarterial extracorporeal membrane oxygenation after coronary artery bypass grafting: Results of a multicenter study. Int J Cardiol. 2017;241:109-114

6. Burrell AJ, Pellegrino VA, Wolfe R, Wong WK, Cooper DJ, Kaye DM, Pilcher DV. Long-term survival of adults with cardiogenic shock after venoarterial extracorporeal membrane oxygenation. J Crit Care. 2015;30:949-956

7. Carroll BJ, Shah RV, Murthy V, McCullough SA, Reza N, Thomas SS, Song TH, Newton-Cheh CH, Camuso JM, MacGillivray T, Sundt TM, Semigran MJ, Lewis GD, Baker JN, Garcia JP. Clinical features and outcomes in adults with cardiogenic shock supported by extracorporeal membrane oxygenation. Am J Cardiol. 2015;116:1624-1630

8. Chen YC, Tsai FC, Chang CH, Lin CY, Jenq CC, Juan KC, Hsu HH, Chang MY, Tian YC, Hung CC, Fang JT, Yang CW. Prognosis of patients on extracorporeal membrane oxygenation: The impact of acute kidney injury on mortality. Ann Thorac Surg. 2011;91:137-142

9. Combes A, Leprince P, Luyt CE, Bonnet N, Trouillet JL, Leger P, Pavie A, Chastre J. Outcomes and long-term quality-of-life of patients supported by extracorporeal membrane oxygenation for refractory cardiogenic shock. Crit Care Med. 2008;36:1404-1411

10. Distelmaier K, Wiedemann D, Binder C, Haberl T, Zimpfer D, Heinz G, Koinig H, Felli A, Steinlechner B, Niessner A, Laufer G, Lang IM, Goliasch G. Duration of extracorporeal membrane oxygenation support and survival in cardiovascular surgery patients. J Thorac Cardiovasc Surg. 2017

11. Distelmaier K, Schrutka L, Binder C, Steinlechner B, Heinz G, Lang IM, Ristl R, Maurer G, Koinig H, Wiedemann D, Rutzler K, Niessner A, Goliasch G. Cardiac arrest does not affect survival in postoperative cardiovascular surgery patients undergoing extracorporeal membrane oxygenation. Resuscitation. 2016;104:24-27

12. Doll N, Fabricius A, Borger MA, Bucerius J, Doll S, Kramer K, Ullmann C, Schmitt DV, Walther T, Falk V, Mohr FW. Temporary extracorporeal membrane oxygenation in patients with refractory postoperative cardiogenic shock-a single center experience. J Card Surg. 2003;18:512-518 
13. Elsharkawy HA, Li L, Esa WA, Sessler DI, Bashour CA. Outcome in patients who require venoarterial extracorporeal membrane oxygenation support after cardiac surgery. J Cardiothorac Vasc Anesth. 2010;24:946-951

14. Fiser SM, Tribble CG, Kaza AK, Long SM, Zacour RK, Kern JA, Kron IL. When to discontinue extracorporeal membrane oxygenation for postcardiotomy support. Ann Thorac Surg. $2001 ; 71: 210-214$

15. Guihaire J, Dang Van S, Rouze S, Rosier S, Roisne A, Langanay T, Corbineau H, Verhoye JP, Flecher E. Clinical outcomes in patients after extracorporeal membrane oxygenation support for post-cardiotomy cardiogenic shock: A single-centre experience of 92 cases. Interact Cardiovasc Thorac Surg. 2017;25:363-369

16. Hsu PS, Chen JL, Hong GJ, Tsai YT, Lin CY, Lee CY, Chen YG, Tsai CS. Extracorporeal membrane oxygenation for refractory cardiogenic shock after cardiac surgery: Predictors of early mortality and outcome from 51 adult patients. Eur J Cardiothorac Surg. 2010;37:328-333

17. Kanji HD, Schulze CJ, Oreopoulos A, Lehr EJ, Wang W, MacArthur RM. Peripheral versus central cannulation for extracorporeal membrane oxygenation: A comparison of limb ischemia and transfusion requirements. Thorac Cardiovasc Surg. 2010;58:459-462

18. Ko WJ, Lin CY, Chen RJ, Wang SS, Lin FY, Chen YS. Extracorporeal membrane oxygenation support for adult postcardiotomy cardiogenic shock. Ann Thorac Surg. 2002;73:538-545

19. Lamarche Y, Chow B, Bedard A, Johal N, Kaan A, Humphries KH, Cheung A. Thromboembolic events in patients on extracorporeal membrane oxygenation without anticoagulation. Innovations (Phila). 2010;5:424-429

20. Li CL, Wang H, Jia M, Ma N, Meng X, Hou XT. The early dynamic behavior of lactate is linked to mortality in postcardiotomy patients with extracorporeal membrane oxygenation support: A retrospective observational study. J Thorac Cardiovasc Surg. 2015;149:1445-1450

21. Liden H, Wiklund L, Haraldsson A, Berglin E, Hultman J, Dellgren G. Temporary circulatory support with extra corporeal membrane oxygenation in adults with refractory cardiogenic shock. Scand Cardiovasc J. 2009;43:226-232

22. Liu KS, Tsai FC, Huang YK, Wu MY, Chang YS, Chu JJ, Lin PJ. Extracorporeal life support: A simple and effective weapon for postcardiotomy right ventricular failure. Artif Organs. 2009;33:504-508

23. Loforte A, Marinelli G, Musumeci F, Folesani G, Pilato E, Martin Suarez S, Montalto A, Lilla Della Monica P, Grigioni F, Frascaroli G, Menichetti A, Di Bartolomeo R, Arpesella G. Extracorporeal membrane oxygenation support in refractory cardiogenic shock: Treatment strategies and analysis of risk factors. Artif Organs. 2014;38:E129-141

24. Luo XJ, Wang W, Hu SS, Sun HS, Gao HW, Long C, Song YH, Xu JP. Extracorporeal membrane oxygenation for treatment of cardiac failure in adult patients. Interact Cardiovasc Thorac Surg. 2009;9:296-300 
25. Mazzeffi MA, Sanchez PG, Herr D, Krause E, Evans CF, Rector R, McCormick B, Pham S, Taylor B, Griffith B, Kon ZN. Outcomes of extracorporeal cardiopulmonary resuscitation for refractory cardiac arrest in adult cardiac surgery patients. J Thorac Cardiovasc Surg. 2016;152:1133-1139

26. Meyer AL, Strueber M, Tomaszek S, Goerler A, Simon AR, Haverich A, Fischer S. Temporary cardiac support with a mini-circuit system consisting of a centrifugal pump and a membrane ventilator. Interact Cardiovasc Thorac Surg. 2009;9:780-783

27. Musial R, Ochonska K, Proc A, Stolinski J, Plicner D, Kapelak B, Drwila R. Veno-arterial extracorporeal membrane oxygenation as cardiogenic shock therapy support in adult patients after heart surgery. Kardiochir Torakochirurgia Pol. 2017;14:32-36

28. Papadopoulos N, Marinos S, El-Sayed Ahmad A, Keller H, Meybohm P, Zacharowski K, Moritz A, Zierer A. Risk factors associated with adverse outcome following extracorporeal life support: Analysis from 360 consecutive patients. Perfusion. 2015;30:284-290

29. Park SJ, Kim SP, Kim JB, Jung SH, Choo SJ, Chung CH, Lee JW. Blood lactate level during extracorporeal life support as a surrogate marker for survival. J Thorac Cardiovasc Surg. 2014; 148:714-720

30. Peigh G, Cavarocchi N, Keith SW, Hirose H. Simple new risk score model for adult cardiac extracorporeal membrane oxygenation: Simple cardiac ecmo score. J Surg Res. 2015;198:273279

31. Pokersnik JA, Buda T, Bashour CA, Gonzalez-Stawinski GV. Have changes in ecmo technology impacted outcomes in adult patients developing postcardiotomy cardiogenic shock? J Card Surg. 2012;27:246-252

32. Pontailler M, Demondion P, Lebreton G, Golmard JL, Leprince P. Experience with extracorporeal life support for cardiogenic shock in the older population more than 70 years of age. ASAIO J. 2017;63:279-284

33. Ranucci M, Ballotta A, Kandil H, Isgro G, Carlucci C, Baryshnikova E, Pistuddi V, Surgical, Clinical Outcome Research G. Bivalirudin-based versus conventional heparin anticoagulation for postcardiotomy extracorporeal membrane oxygenation. Crit Care. 2011;15:R275

34. Rastan AJ, Dege A, Mohr M, Doll N, Falk V, Walther T, Mohr FW. Early and late outcomes of 517 consecutive adult patients treated with extracorporeal membrane oxygenation for refractory postcardiotomy cardiogenic shock. J Thorac Cardiovasc Surg. 2010;139:302-311, 311 e301

35. Rousse N, Juthier F, Pincon C, Hysi I, Banfi C, Robin E, Fayad G, Jegou B, Prat A, Vincentelli A. Ecmo as a bridge to decision: Recovery, vad, or heart transplantation? Int $\mathrm{J}$ Cardiol. 2015;187:620-627

36. Rubino A, Costanzo D, Stanszus D, Valchanov K, Jenkins D, Sertic F, Fowles JA, Vuylsteke A. Central veno-arterial extracorporeal membrane oxygenation (c-va-ecmo) after cardiothoracic surgery: A single-center experience. J Cardiothorac Vasc Anesth. 2017

37. Russo CF, Cannata A, Lanfranconi M, Bruschi G, Milazzo F, Paino R, Martinelli L. Veno-arterial extracorporeal membrane oxygenation using levitronix centrifugal pump as bridge to decision 
for refractory cardiogenic shock. J Thorac Cardiovasc Surg. 2010;140:1416-1421

38. Saxena P, Neal J, Joyce LD, Greason KL, Schaff HV, Guru P, Shi WY, Burkhart H, Li Z, Oliver WC, Pike RB, Haile DT, Schears GJ. Extracorporeal membrane oxygenation support in postcardiotomy elderly patients: The mayo clinic experience. Ann Thorac Surg. 2015;99:20532060

39. Slottosch I, Liakopoulos O, Kuhn E, Deppe AC, Scherner M, Madershahian N, Choi YH, Wahlers T. Outcomes after peripheral extracorporeal membrane oxygenation therapy for postcardiotomy cardiogenic shock: A single-center experience. J Surg Res. 2013;181:e47-55

40. Slottosch I, Liakopoulos O, Kuhn E, Scherner M, Deppe AC, Sabashnikov A, Mader N, Choi YH, Wippermann J, Wahlers T. Lactate and lactate clearance as valuable tool to evaluate ecmo therapy in cardiogenic shock. J Crit Care. 2017;42:35-41

41. Truby L, Mundy L, Kalesan B, Kirtane A, Colombo PC, Takeda K, Fukuhara S, Naka Y, Takayama $\mathrm{H}$. Contemporary outcomes of venoarterial extracorporeal membrane oxygenation for refractory cardiogenic shock at a large tertiary care center. ASAIO J. 2015;61:403-409

42. Tsai TY, Tsai FC, Fan PC, Chang CH, Lin CY, Chang WW, Lee SY, Hsu HH, Tian YC, Fang JT, Yang $\mathrm{CW}$, Chen YC. Application of the age, creatinine, and left ventricular ejection fraction score for patients on extracorporeal membrane oxygenation. Artif Organs. 2017;41:146-152

43. Wang J, Han J, Jia Y, Zeng W, Shi J, Hou X, Meng X. Early and intermediate results of rescue extracorporeal membrane oxygenation in adult cardiogenic shock. Ann Thorac Surg. 2009;88:1897-1903

44. Wang JG, Han J, Jia YX, Zeng W, Hou XT, Meng X. Outcome of veno-arterial extracorporeal membrane oxygenation for patients undergoing valvular surgery. PLoS One. 2013;8:e63924

45. Wu MY, Lin PJ, Lee MY, Tsai FC, Chu JJ, Chang YS, Haung YK, Liu KS. Using extracorporeal life support to resuscitate adult postcardiotomy cardiogenic shock: Treatment strategies and predictors of short-term and midterm survival. Resuscitation. 2010;81:1111-1116

46. Xie HX, Yang F, Jiang CJ, Wang JH, Hou DB, Wang JG, Wang H, Hou XT. [predictors of in-hospital mortality in adult postcardiotomy cardiacgenic shock patients successfully weaned from venoarterial extracorporeal membrane oxygenation]. Zhonghua Yi Xue Za Zhi. 2017;97:929-933

47. Zhang R, Kofidis T, Kamiya H, Shrestha M, Tessmann R, Haverich A, Klima U. Creatine kinase isoenzyme mb relative index as predictor of mortality on extracorporeal membrane oxygenation support for postcardiotomy cardiogenic shock in adult patients. Eur $\mathrm{J}$ Cardiothorac Surg. 2006;30:617-620

48. Zhao Y, Xing J, Du Z, Liu F, Jia M, Hou X. Extracorporeal cardiopulmonary resuscitation for adult patients who underwent post-cardiac surgery. Eur J Med Res. 2015;20:83

49. Zhong Z, Jiang C, Yang F, Hao X, Xing J, Wang H, Hou X. Veno-arterial extracorporeal membrane oxygenation support in patients undergoing aortic surgery. Artif Organs. 2017;41:1113-1120

50. Ariyaratnam P, McLean LA, Cale AR, Loubani M. Extra-corporeal membrane oxygenation for the post-cardiotomy patient. Heart Fail Rev. 2014;19:717-725 
51. Deschka H, Machner M, El Dsoki S, Alken A, Wimmer-Greinecker G. Central closed chest implantation of extracorporeal membrane oxygenation to prevent limb ischemia. Int J Artif Organs. 2013;36:687-692

52. Khorsandi M, Shaikhrezai K, Prasad S, Pessotto R, Walker W, Berg G, Zamvar V. Advanced mechanical circulatory support for post-cardiotomy cardiogenic shock: A 20-year outcome analysis in a non-transplant unit. J Cardiothorac Surg. 2016;11:29

53. Mikus E, Tripodi A, Calvi S, Giglio MD, Cavallucci A, Lamarra M. Centrimag venoarterial extracorporeal membrane oxygenation support as treatment for patients with refractory postcardiotomy cardiogenic shock. ASAIO J. 2013;59:18-23

54. Raffa GM, Gelsomino S, Sluijpers N, Meani P, Alenizy K, Natour E, Bidar E, Johnson DM, Makhoul M, Heuts S, Lozekoot P, Kats S, Schreurs R, Delnoij T, Montalti A, Sels JW, Poll MV, Roekaerts P, Maessen J, Lorusso R. In-hospital outcome of post-cardiotomy extracorporeal life support in adult patients: The 2007-2017 maastricht experience. Crit Care Resusc. 2017;19:53-61

55. Unosawa S, Sezai A, Hata M, Nakata K, Yoshitake I, Wakui S, Kimura H, Takahashi K, Hata H, Shiono M. Long-term outcomes of patients undergoing extracorporeal membrane oxygenation for refractory postcardiotomy cardiogenic shock. Surg Today. 2013;43:264-270

\section{Tables}

Table 1. Study characteristics.

Due to technical limitations, Table 1 is only available as a download in the supplemental files section.

\section{Figures}




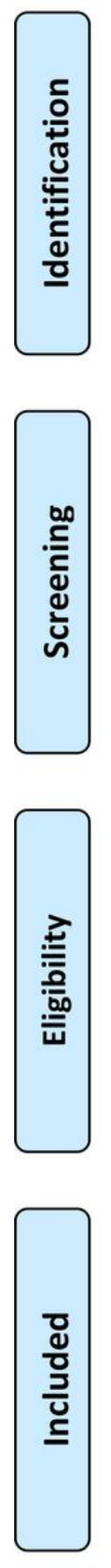

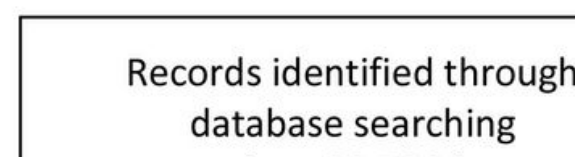

( $n=22,586)$

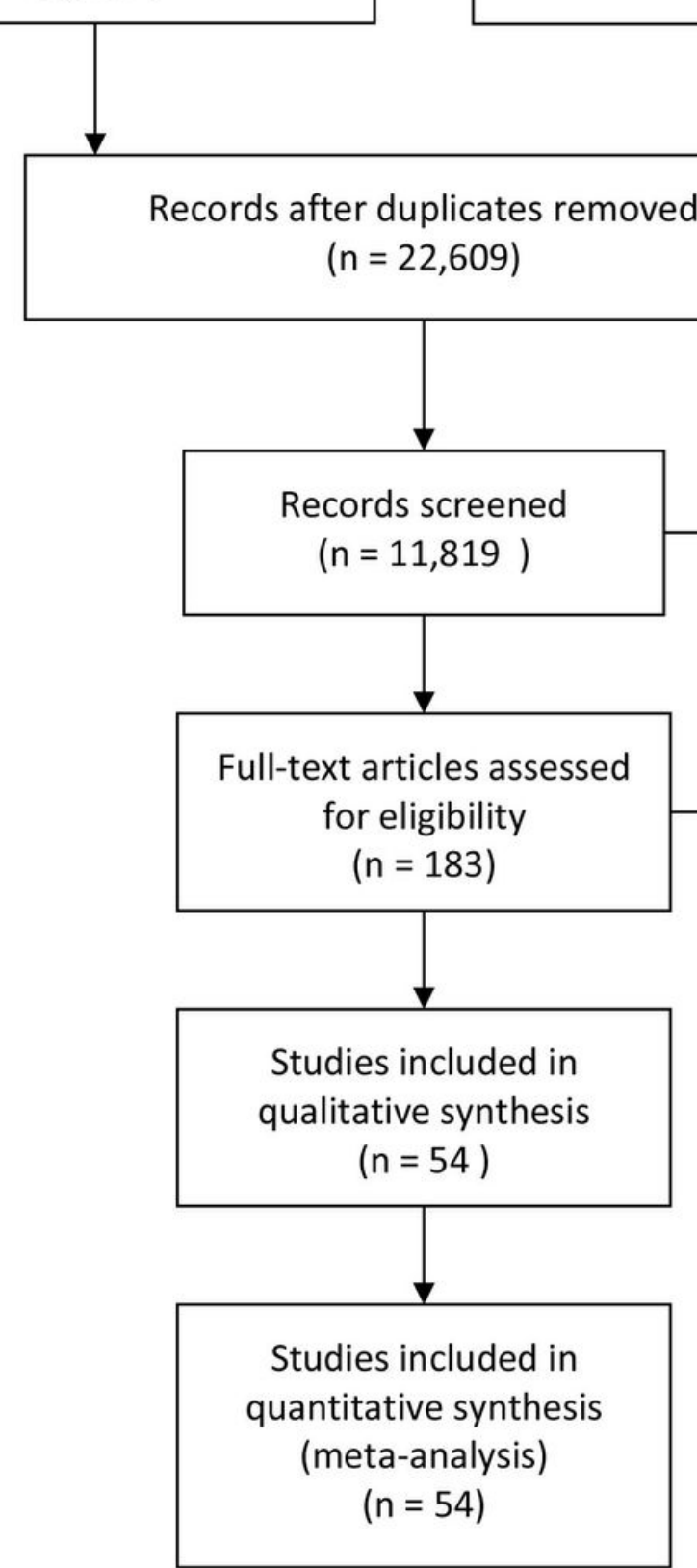

Additional records identified through other sources

$$
(n=23)
$$




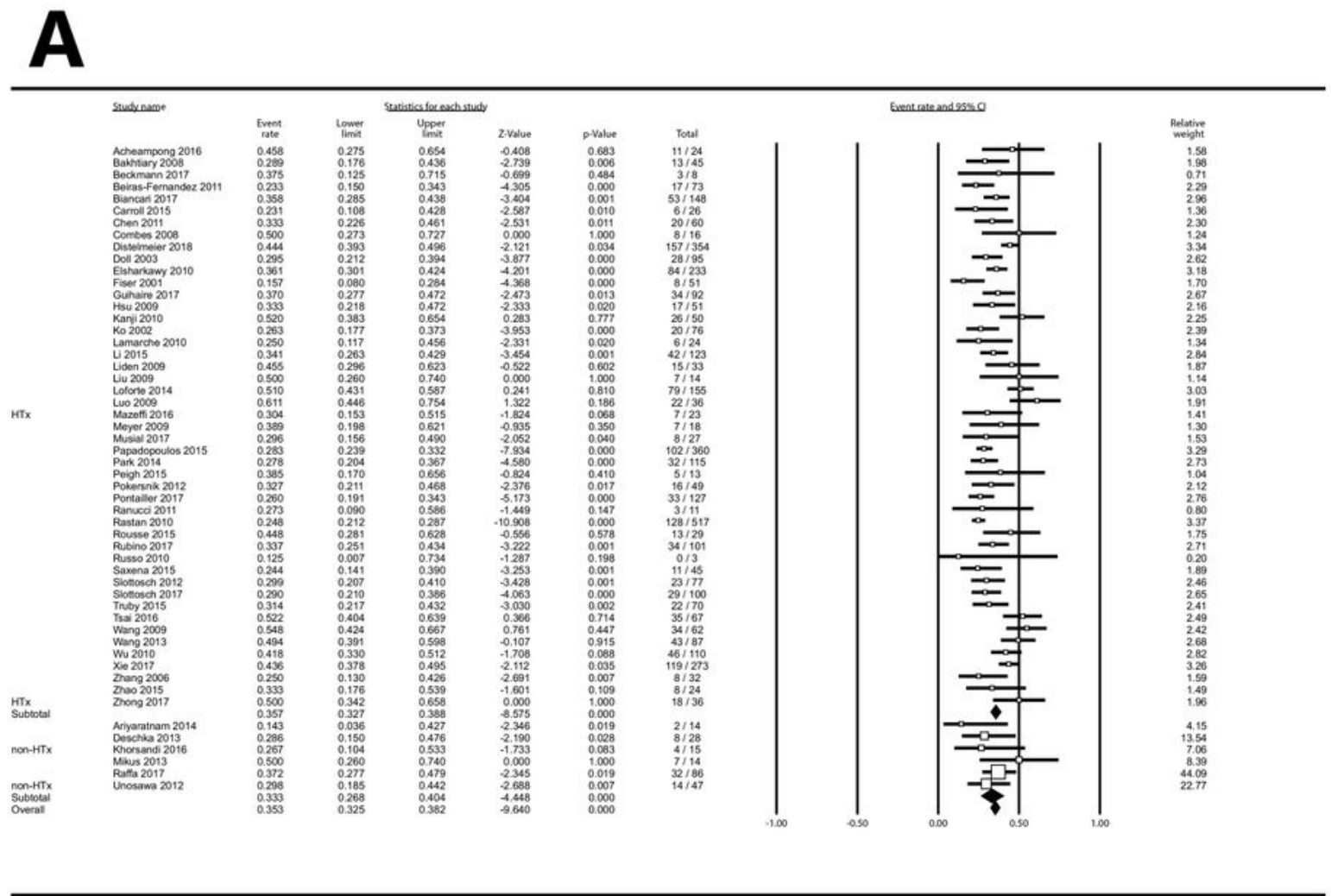

B

\section{Regression of ECMO per year on Logit event rate}

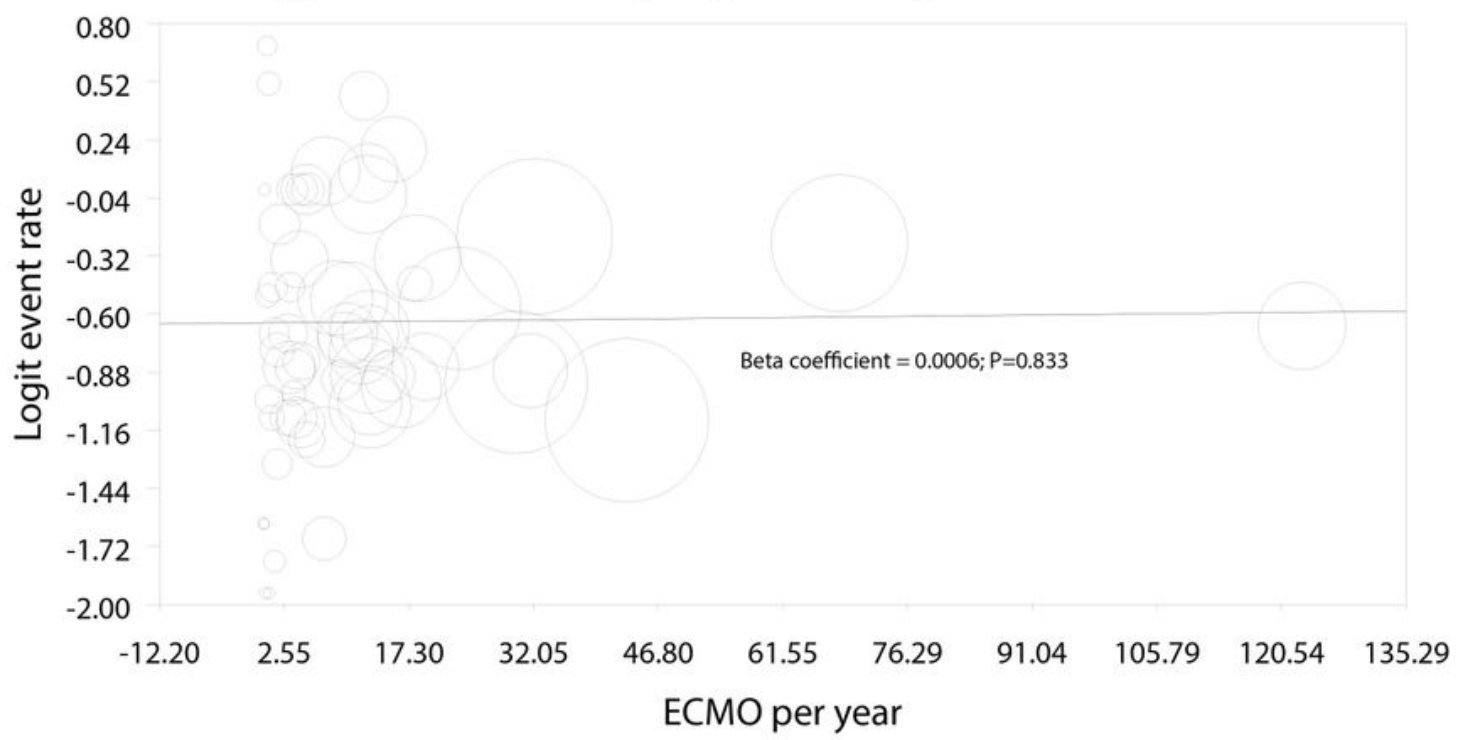

Figure 2

Analysis of survival after following ECMO institution in HTx/VAD vs non-HTx/VAD centres. Squares represent point estimates of single studies; horizontal lines are respective $95 \%$ confidence intervals. Diamonds are indicative of subtotal and total pooled estimate (A). Meta-regression analysis of number of ECMOs per year on logit survival event rate (B). HTx, heart transplantation; VAD, ventricle assist device. 
A

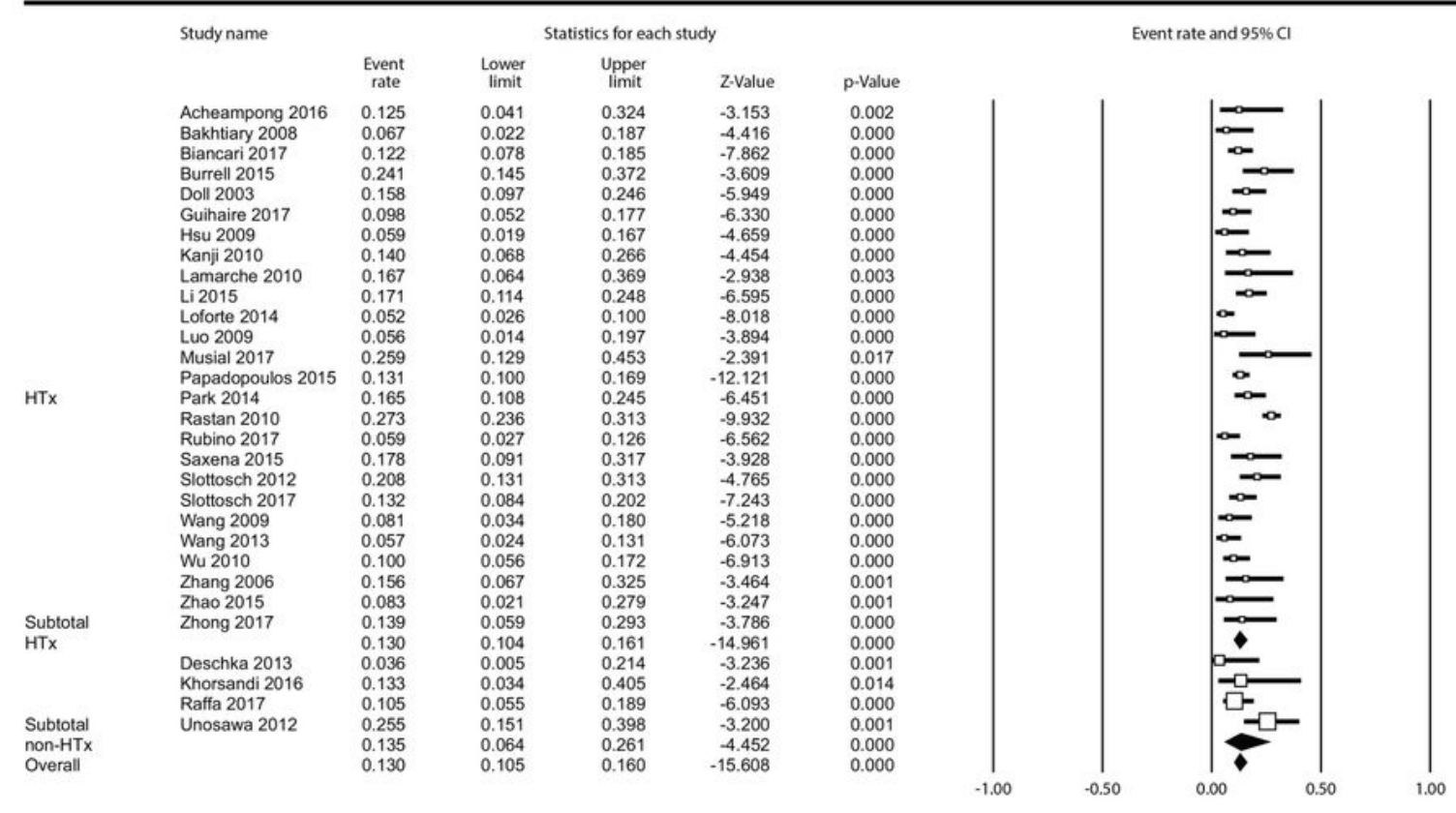

B

\section{Regression of ECMO per year on Logit event rate}

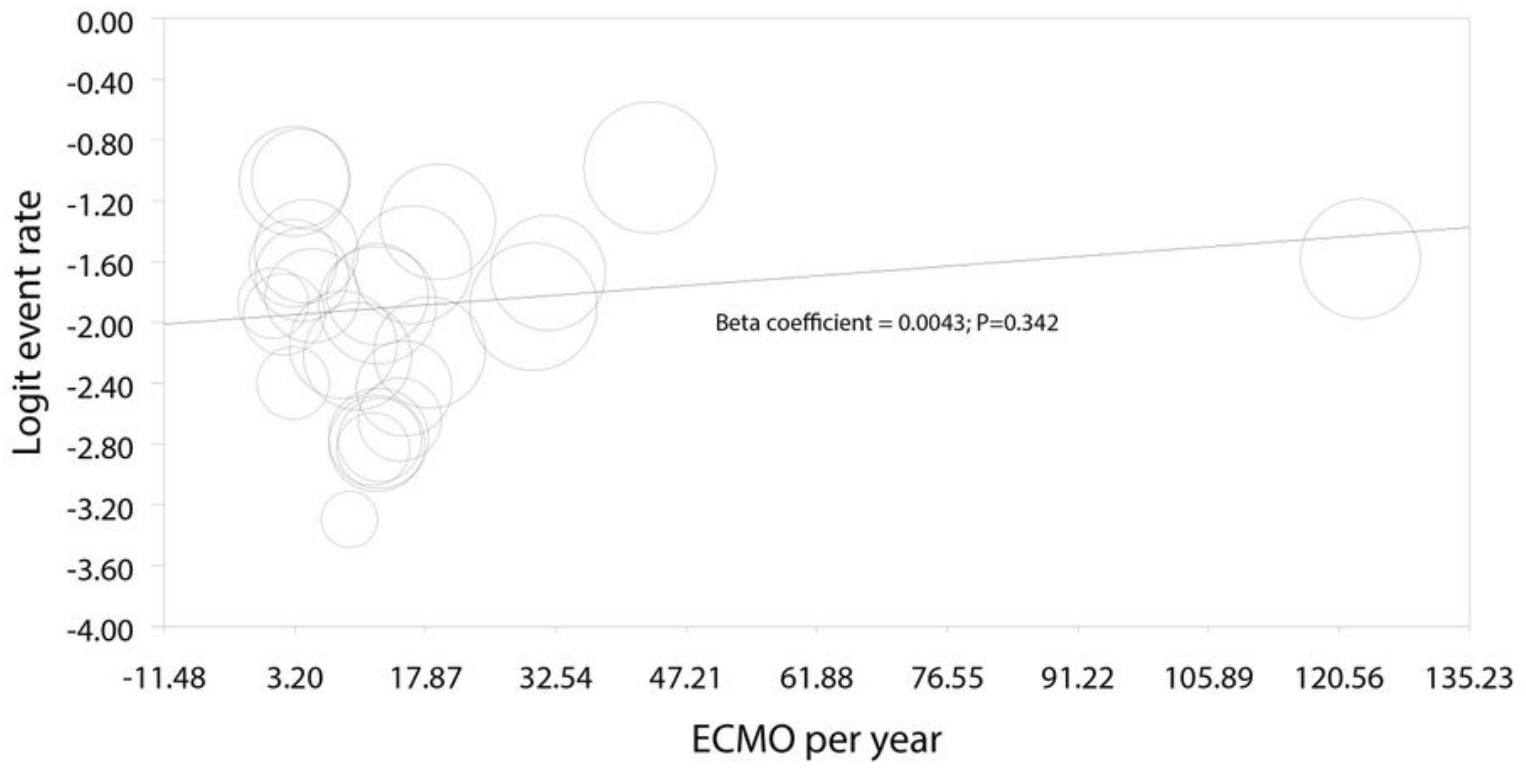

Figure 3

Analysis of limb complications following ECMO institution in HTx/VAD vs non-HTx/VAD centres (A). Meta-regression analysis of number of ECMOs per year on logit limb complications event rate (B). Abbreviations as in Figure 1. 
A

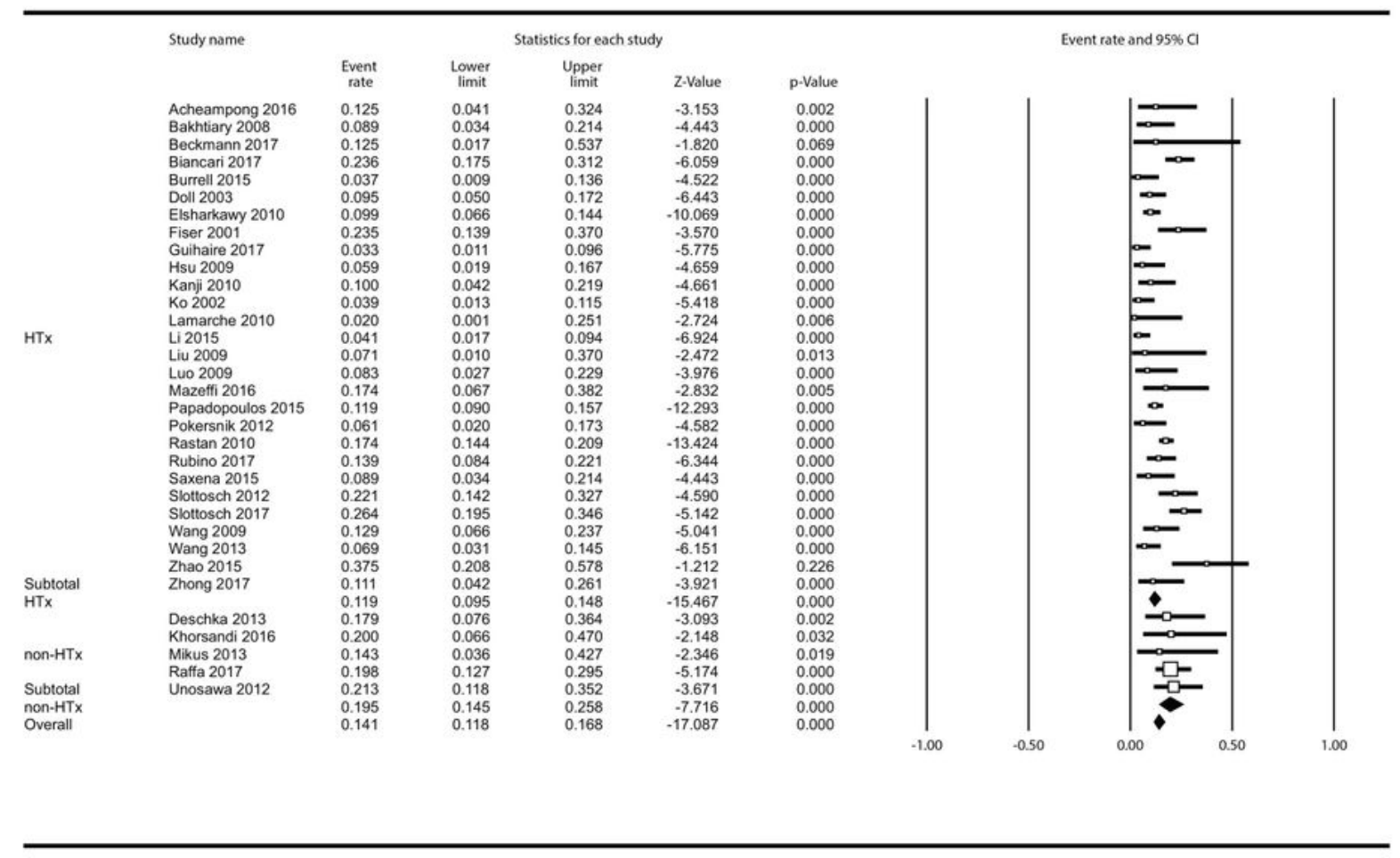

B

Regression of ECMO per year on Logit event rate

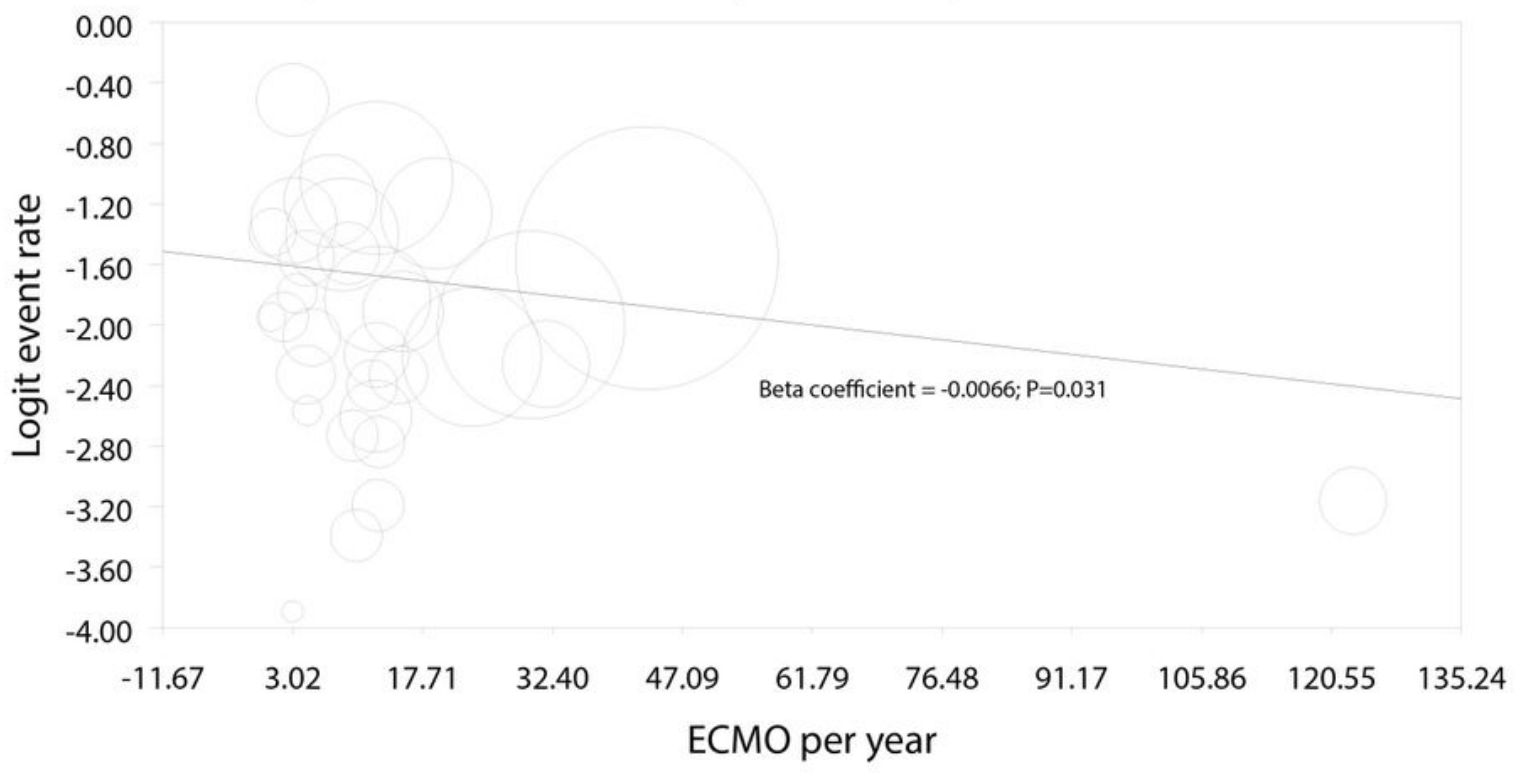

\section{Figure 4}

Analysis of neurologic complications (A) following ECMO institution in HTx/VAD vs non-HTx/VAD centres (A). Meta-regression analysis of number of ECMOs per year on logit neurologic complications event rate (B). Abbreviations as in Figure 1. 


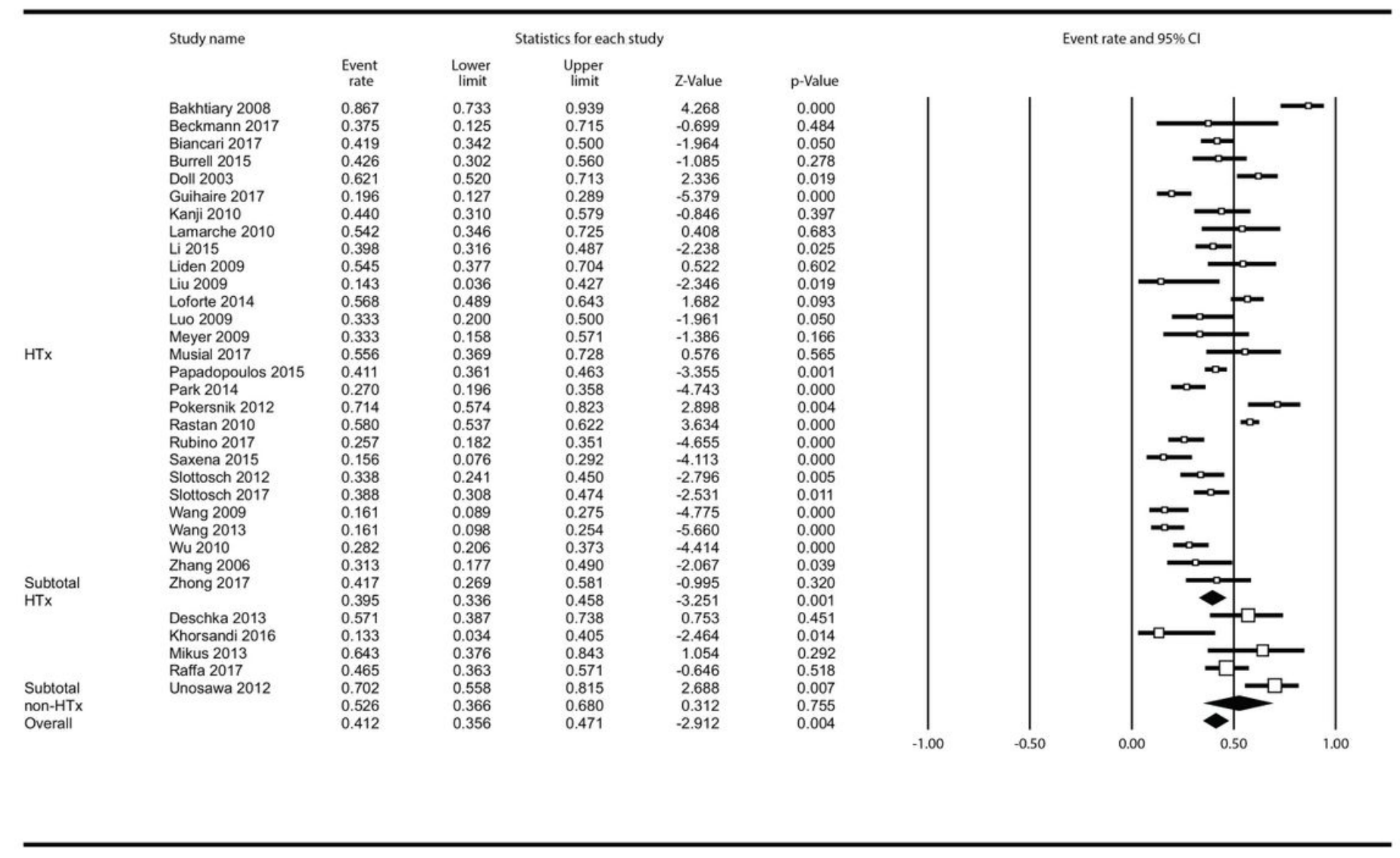

\section{Figure 5}

Analysis of reoperations for bleeding following ECMO institution in HTx/VAD vs non-HTx/VAD centres. Remaining abbreviations as in Figure 1. 


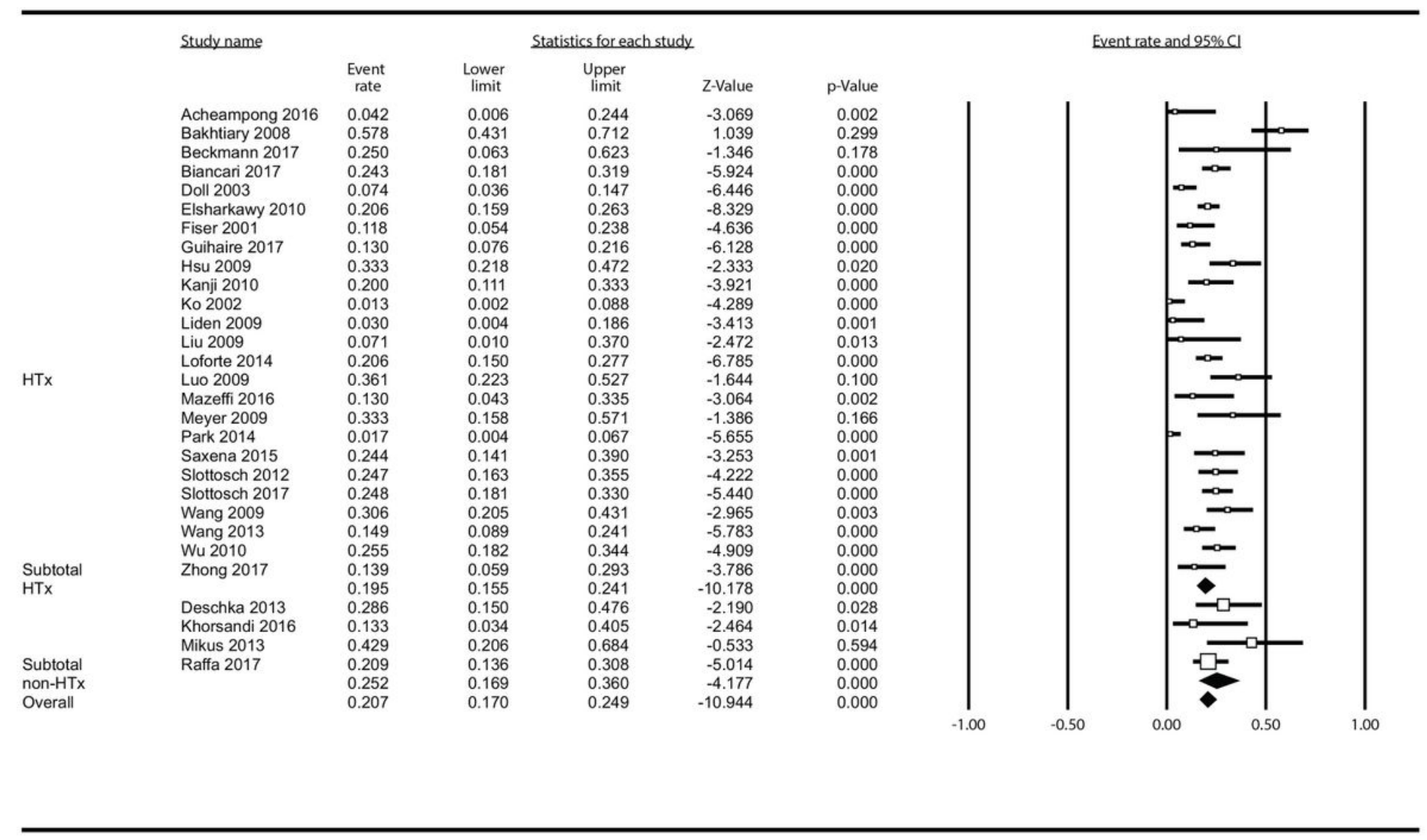

Figure 6

Analysis of sepsis following ECMO institution in HTx/VAD vs non-HTx/VAD centres. Remaining abbreviations as in Figure 1. 


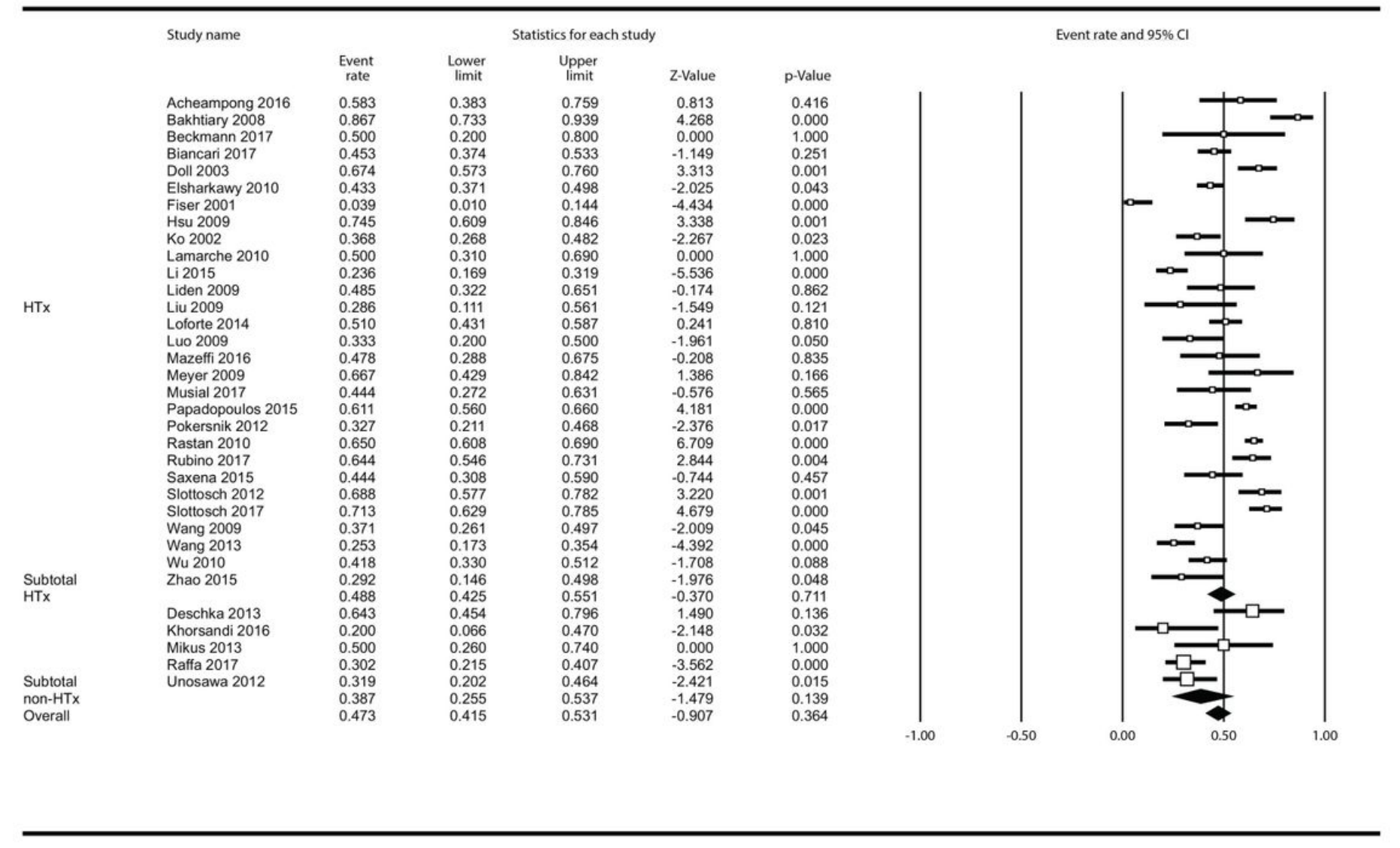

Figure 7

Analysis of acute kidney injury following ECMO institution in HTx/VAD vs non-HTx/VAD centres.

Remaining abbreviations as in Figure 1.

\section{Supplementary Files}

This is a list of supplementary files associated with this preprint. Click to download.

- MK20.032019ECMOinHTxsupplement.docx

- Table1.pdf 